\title{
PHYTOCHEMISTRY AND ANTIOXIDANT ACTIVITY OF SOURSOP (ANNONA MURICATA) LEAVES
}

\author{
FONA QORINA ${ }^{1}$, ADE ARSIANTI ${ }^{2,3^{*}}$, QOTRUNNADA FITHROTUNNISA ${ }^{1}$, NADZILA ANINDYA TEJAPUTRI ${ }^{1}$
}

${ }^{1}$ Medical Student, Faculty of Medicine, Universitas Indonesia, ${ }^{2}$ Department of Medical Chemistry, Faculty of Medicine, Universitas Indonesia, ${ }^{3}$ Drug Development Research Cluster, Indonesia Medical Education and Research Institute (IMERI), Faculty of Medicine, Universitas Indonesia

Email: arsi_ade2002@yahoo.com

Received: 15 Dec 2018, Revised and Accepted: 10 Mar 2019

\section{ABSTRACT}

Objective: Soursop (Annona muricata) is a tropical plant which has been utilized as a folk medicine to treat many diseases including cancer, inflammation and parasitic infection. In this study, we investigated its phytochemistry properties and antioxidant activity against free radicals.

Methods: Annona muricata leaves were extracted in three different solvents: ethanol, ethyl acetate and n-hexane. Afterwards, a phytochemistry test and the thin layer chromatography (TLC) method were used to evaluate bioactive compounds contained in the three different extracts. Antioxidant activity from the semi-polar (ethyl acetate) and polar (ethanol) solvents were evaluated by the DPPH (1,1-diphenyl-2-picrylhydrazyl) method, and the antioxidant activity is expressed by $\mathrm{IC}_{50}$ value. The results were compared to ascorbic acid as a positive control.

Results: The phytochemistry test showed that the extracts were positive for flavonoids, steroids, alkaloids, glycosides and tannins. Moreover, TLC analysis revealed that there were three chemical compounds contained in the extracts. The results from the DPPH method were that ethanolic extract was shown to have the most potent antioxidant activity with an $\mathrm{IC}_{50}$ value of $35.51 \mathrm{ppm}$.

Conclusion: The ethanolic extract of Annona muricata could be developed as the next promising natural antioxidant source.

Keywords: Antioxidants, DPPH method, Phytochemiscals, Soursop

(C) 2019 The Authors. Published by Innovare Academic Sciences Pvt Ltd. This is an open access article under the CC BY license (http://creativecommons. org/licenses/by/4. 0/) DOI: http://dx.doi.org/10.22159/ijap.2019.v11s6.33524

\section{INTRODUCTION}

Oxidative stress is a condition that occurs when an imbalance between the amount of reactive oxygen-nitrogen species (RONS) and free radical defense mechanism, or antioxidants, leads to a disruption of redox signaling [1, 2]. RONS are by-products of normal cellular metabolism known to have beneficial effects as signaling molecules for inflammation, wound healing and tissue regeneration [1]. RONS also plays an important role in cell homeostasis and fighting pathogens. Unfortunately, an excessive number of RONS tends to initiate free radical reactions, which result in irreversible DNA damage, protein changes, cellular dysfunction and cytotoxicity. Free radicals are very reactive molecules which can pull electrons to complete their orbital. Increasing evidence suggests that RONS and oxidative stress play a causative role in chronic disease pathogenesis, such as cancer, neurodegenerative disease, cardiovascular disease and metabolic disease $[3,4]$.

Adaptive response is one of the important defense mechanisms to prevent oxidative stress. The body generates endogenous enzymatic antioxidants such as superoxide dismutase, catalase, glutathione peroxidase and non-enzymatic antioxidants to stabilize free radicals and inhibit oxidative damage. However, exogenous oxidants such as cigarette smoke, ozone exposure, hyperoxia, ionizing radiation and heavy metal ions also play a crucial role for formation of reactive radicals and extensive cellular damage [2]. Insufficient antioxidant defense mechanisms will lead to oxidative stress and the development of chronic diseases. However, antioxidant supplements do not possess preventive effects and may be harmful to the body. For example, butylated hydroxytoluene (BHT) is an antioxidant supplement reported to have carcinogenic effects [5].

Much research is focused on alternatives for exogenous antioxidants from dietary sources, especially from natural products like herbs because of their safety and potential therapeutic values. Metabolic compounds found in plants, such as polyphenols and flavonoids, are known to play a role in scavenging free radicals because of their redox properties $[6,7]$.

The genus Annona, which includes such species as A. muricata, A. squamosa, $A$. senegalensis and $A$. cherimoya, are known to have important pharmacological properties that treat many illnesses because it is rich in phenolic compounds [8]. Soursop (Annona muricata) or sirsak is a tropical plant species widely cultivated across Southeast Asia, including Indonesia. Different parts of the plants, especially its leaves, are known to have health benefits. Annona muricata leaves are usually used as alternative therapy to cure cancer and parasitic infection. M Pai et al. found that soursop extract has antimicrobial and fungicidal properties when used against oral microbiota [9]. Another study conducted by Astirin et al. reported that extract of $A$. muricata activates the apoptosis process due to an increase in p53 expression in a cancer environment [10]. Padma et al. showed that ethanolic extract of $A$. muricata caused a reduction in lipid peroxidation and increased protective effects against oxidative stress induced by carbon tetrachloride. In addition, the stem extracts also significantly increased oxidant levels [11]. According to previous research on A. muricata leaves, the formation of lipid free radicals in malondialdehyde (MDA) is reduced by application of soursop leaves in colon cancer HT-29 cells [12].

Studies about phytochemistry and the antioxidant activity of ethanolic, ethyl acetate and $n$-hexane extracts of Annona muricata leaves in Indonesia are still limited. Hence, mechanisms of action underlying the potency of $A$. muricata extracts as antioxidants remain questionable. Therefore, the aims of this research are to analyze phytochemistry profiles and evaluate antioxidant activity of three different $A$. muricata extracts by DPPH assay.

\section{MATERIALS AND METHODS}

\section{Collection of materials}

Soursop leaves (Annona muricata) were collected from Tangerang, West Java, Indonesia in the month of January 2018. The leaves were then dried and ground, and about 100 grams of dry powder was obtained.

\section{Extraction and fractionation of soursop leaves sample}

At Bogor Agricultural University, Annona muricata leaves were macerated using three different solvents: ethanol, ethyl acetate, and n-hexane. This procedure started with dissolving A. muricata dry powder in 2-hexane $500 \mathrm{ml}$ for $24 \mathrm{~h}$. It was then filtered twice until 
it became solid with a liquid filtrate of n-hexane. The solid filtrate from each solution was then fractionated and concentrated, resulting in ethanolic and ethyl acetate extracts.

\section{Thin layer chromatography}

Thin layer chromatography (TLC) is a chromatography method that identifies and separates chemical substances based on polarity of the compounds. TLC consists of a stationary phase and a mobile phase. The stationary phase is the TLC plate combined with adsorbent material, such as silica gel. In this study, chloroform $\left(\mathrm{CHCl}_{3}\right)$-methanol $\left(\mathrm{CH}_{3} \mathrm{OH}\right)$ was used as the eluent in the mobile phase with a 4:1 ratio. Afterwards, a sample from each solvent was dripped on the plate. Then, the TLC plate was placed into the chamber of eluent. Chemical components contained in the solutions move at different rates depending on their polarity and solubility.

The result of this procedure is demonstrated by the retention factor (Rf), which is defined as the distance traveled by the sample compared to the solvent. Furthermore, the plate was visualized in ultraviolet (UV) light to see how many compounds were contained in the extracts. The formula to determine the retention factor was:

$$
\begin{gathered}
\text { Rf }(\text { Retention factor })=\text { distance traveled by sample/distance } \\
\text { traveled by solvent }
\end{gathered}
$$

Bioactive substances contained in ethyl acetate, ethanolic and nhexane extracts of $A$. muricata can be identified through several qualitative phytochemistry tests, such as the flavonoid test, saponin test, triterpene and steroid test, alkaloid test, glycoside test, and tannin test.

\section{Flavonoid test}

A $1 \mathrm{ml}$ sample from each extract was dissolved in methanol and evaporated. Next, the residue was dissolved with acetone, powder of boric acid and oxalic acid. Next, ether $10 \mathrm{ml}$ was added to the mixture. Finally, the mixture was observed with a $365 \mathrm{~nm}$ UV wavelength. A positive result was indicated by yellow fluorescence.

\section{Saponin test}

A $1 \mathrm{mg}$ sample from each solvent was dissolved in methanol $10 \mathrm{ml}$. The tube was then shaken for approximately 10 seconds. A positive result was indicated by the presence of stabile foam in less than $10 \mathrm{~min}$.

\section{Triterpene and steroid test}

The Liebermann-Burchard reaction for steroids was used for this test. Approximately $2 \mathrm{ml}$ from each extract were evaporated, and the remaining solution was dissolved in chloroform $0.5 \mathrm{ml}$ and anhydrate acetate acid $0.5 \mathrm{ml}$. Next, concentrated sulfuric acid $2 \mathrm{ml}$ was dripped into the tube. A positive result for steroids was indicated by formation of a blue-green ring. Meanwhile, the presence of a red ring indicated a positive result for triterpenes.

\section{Alkaloid test}

Approximately $2 \mathrm{ml}$ of each extract were evaporated until they dried. Subsequently, $5 \mathrm{ml}$ of hydrochloric acid $2.0 \mathrm{~N}$ was added and the mixture was distributed among three different tubes. The first tube was filled with $\mathrm{HCl} 2.0 \mathrm{~N}$ only. Dragendorff reagent was added to the second tube, and Meyer reagent was added to the third tube. The formation of orange precipitate in the second tube and yellow precipitate in the third tube indicated positive results.

\section{Glycoside test}

A $0.1 \mathrm{ml}$ solution from each solvent was evaporated in a water bath. Next, anhydrate acetate acid $5 \mathrm{ml}$ and ten drops of concentrated sulfuric acid were added to the remaining solution. Changes in the solution's color to blue or green indicated positive results.

\section{Tannin test}

A $1 \mathrm{mg}$ of sample was dissolved in methanol $1 \mathrm{ml}$. Next, the mixture was dissolved in Fe(III) Chloride 10\%. Formation of a dark blue or green color indicated a positive result for tannins.

\section{Analysis of antioxidant activity}

Antioxidant activity of A. muricata was evaluated by DPPH (2,2diphenyl-1-picrylhydrazyl) assay in the Drug Development Research Cluster of the Indonesian Medical Research Institute (IMERI) at the University of Indonesia. This assay is based on the theory that antioxidants can act as hydrogen donors to stabilize free radicals. DPPH is one of the few available stable organic nitrogen radicals at room temperature.

This procedure began with the addition of a $100 \mu \mathrm{M}$ sample from ethanol and ethyl acetate extracts into the microtubes. Next, DPPH $2.9 \mathrm{ml}$ at $0.004 \%$ concentration in methanol was added to the samples and to ascorbic acid as a positive control. All microtubes were kept in the dark for 90 min at room temperature. Absorbance was measured with a spectrophotometer using a $515 \mathrm{~nm}$ wavelength. Lower absorbance of the reaction indicated higher free radical DPPH scavenging activity. The results were then compared to ascorbic acid as a positive control per gram of sample dry weight. Analysis of antioxidant activity was measured using the following equation:

DPPH inhibition (\%) = (absorbance of control-absorbance of sample)/absorbance of control) $\times 100 \%$

\section{RESULTS AND DISCUSSION}

\section{Phytochemistry profile of Annona muricata}

A plant's phytochemistry profile plays a crucial role in pharmaceutical discovery. Identification of bioactive compounds leads to analysis of a possible mechanism of action. Secondary metabolites found in Annona muricata are shown in table 1.

Table 1: Phytochemistry profile of Annona muricata

\begin{tabular}{llll}
\hline Metabolites & Extract & Ethanol \\
\cline { 2 - 4 } & Ethyl acetate & + & n-Hexane \\
\hline Flavonoid & + & - & - \\
Saponin & - & - & - \\
Triterpene & - & + & + \\
Steroid & + & + & + \\
Alkaloid & + & + & - \\
Glycoside & + & + & + \\
Tannin & - & & + \\
\hline
\end{tabular}

According to qualitative tests for bioactive compounds, A. muricata extract contains flavonoids, steroids, glycosides, alkaloids and tannins. Flavonoids, steroids and glycosides were positive in three different extracts. Meanwhile, saponin and triterpene tests were negative. Alkaloids were present both in ethanol and ethyl acetate extracts. However, tannins were only positive in the ethanolic extract.
Many in vitro studies suggest that phenolic compounds, including flavonoids, have considerable antioxidant activity [6]. There is a positive correlation between free radical scavenging and total phenolic content. Antioxidant activity of phenolic compounds is mainly due to their redox properties, which allow them to act as hydrogen donors and reducing agents $[13,14]$. Flavonoids, steroids and alkaloids found in the extracts also contribute to the antimicrobial bioactivity of $A$. 
muricata [15]. Secondary metabolite alkaloids have several benefits to health, such as a hypotensive effect, the ability to inhibit RNA synthesis of microorganisms, antidepressant effects, and antiparasitic properties $[16,17]$. Steroid compounds are well known for their ability to inhibit progression of cancer. Tannins have antimicrobial effects for the prevention of oral diseases related to dental biofilms, [9] and they inhibit alfa-glucosidase, which has a hypoglycemic effect [18]. Whereas glycosides are associated with a plant's nutritional quality. These qualitative findings offer scientific validation for further in vitro and in vivo research regarding compound identification.

\section{Thin layer chromatography}

The results of TLC analysis of Annona muricata extracts are summarized. Evaluation of secondary metabolites by TLC analysis shows that three different extracts contain three spots with the same Rf values at $0.771,0.857$ and 0.971 , respectively. The retention factor was calculated by the following equation:

Rf (Retention factor) = distance traveled by sample/distance traveled by solvent.

Visualization in UV and non-UV light is shown in fig. 1, which also revealed that ethyl acetate, ethanolic and n-hexane extracts have three similar spots. As explained above, phytochemistry test results were positive for flavonoids, steroids, and glycosides for the three extracts. This matches the TLC analysis in three similar secondary metabolites. A greater retention factor indicates lower polarity of the chemical components because interaction with the plate is stronger than the adsorbent [19].

Table 2: TLC results and retention factor (Rf) of Annona muricata

\begin{tabular}{llll}
\hline Extract & Rf value & & $\mathbf{3}$ \\
\cline { 2 - 4 } & $\mathbf{1}$ & $\mathbf{2}$ & 0.971 \\
\hline Ethyl Acetate & 0.771 & 0.857 & 0.971 \\
Ethanol & 0.771 & 0.857 & 0.971 \\
n-Hexane & 0.771 & 0.857 & \\
\hline
\end{tabular}
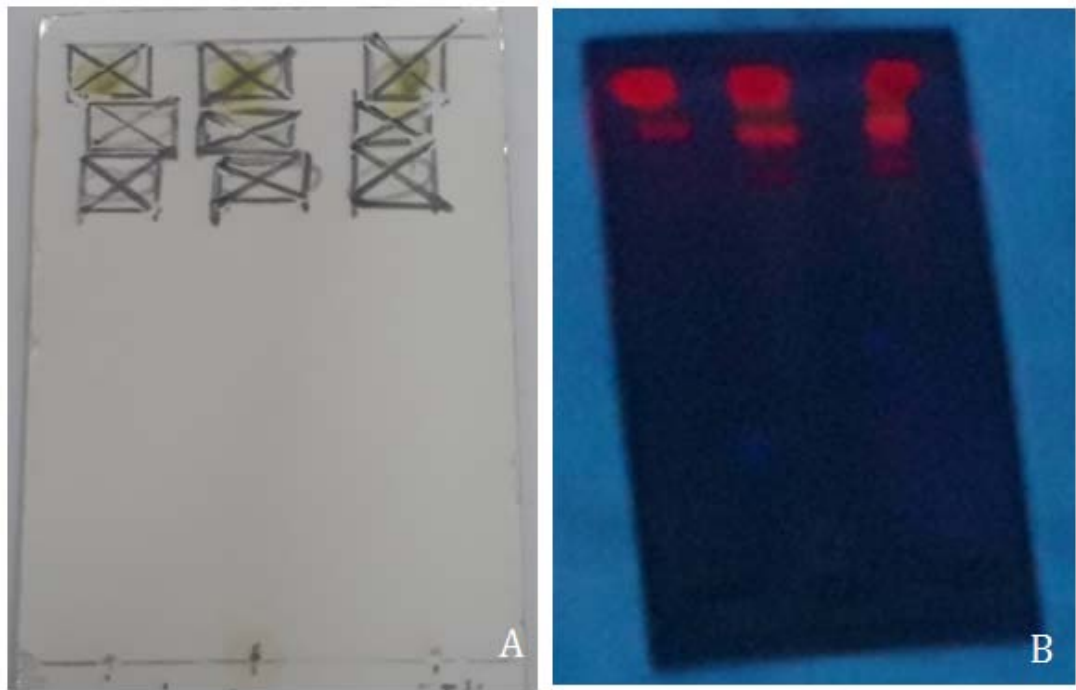

Fig. 1: TLC result of n-hexane, ethanol, and ethyl acetate extracts (from left to right) of $A$. muricata. (a) appearance without UV light. (b) appearance with UV light, retention factor of three spots in these three extracts are the same

\section{Analysis of antioxidant activity}

Antioxidants are molecules which can inhibit free radical reaction by donating their hydrogen atoms [2] In this study, we evaluated antioxidant activity of the A. muricata extracts to free radical DPPH. $\mathrm{DPPH} \bullet$ is an organic reactive nitrogen species (RNS), which turns from the color purple to yellow followed by the formation of a stable DPPH compound upon donation of hydrogen from an antioxidant, as illustrated in fig. 2 [20]. Interpretation of DPPH activity is measured by the amount of IC ${ }_{50}$ or substrate concentration, which can cause a $50 \%$ loss of DPPH activity. A smaller IC $\mathrm{C}_{50}$ value means greater inhibition of free radicals and stronger extract potency as an antioxidant [21]. Results from the analysis of $A$. muricata antioxidant activity with ethanol and ethyl acetate extracts are shown in table 3 and table 4, respectively.
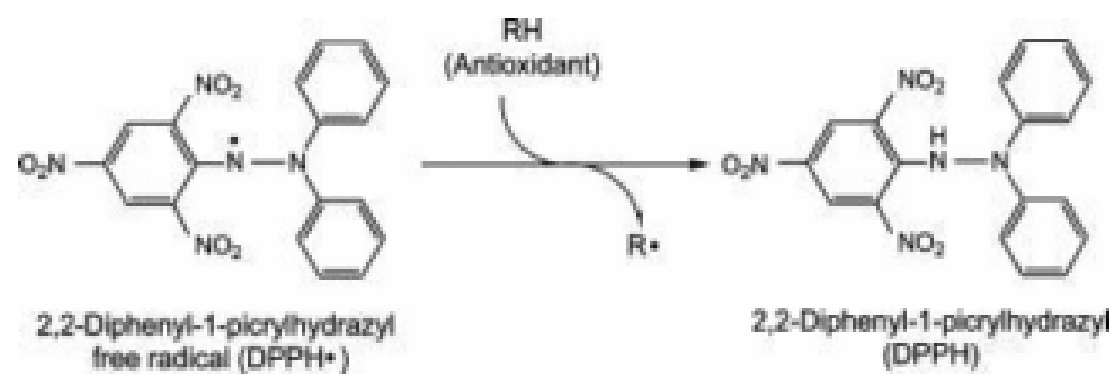

Fig. 2: DPPH• free radical conversion to DPPH by antioxidant compound [20] 
Table 3: Antioxidant activity of ethanolic extract of $A$. muricata

\begin{tabular}{lll}
\hline Concentrations of $\boldsymbol{A}$. muricata ethanol extract & \% Inhibition \\
\hline 3.75 & 0.0242 & -2.0 \\
6.25 & 0.0159 & 0.7 \\
12.5 & 0.0662 & 3.2 \\
25 & 0.0548 & 34.7 \\
50 & 0.0728 & 72.1 \\
\hline
\end{tabular}

A linear regression equation of $\mathrm{y}=1.5647 \mathrm{x}-5.5685$ (with $\mathrm{R}^{2}=0.9961$ ) is utilized to generate the $\mathrm{IC}_{50}$ value of the ethanolic extract of $A$. muricata, by substitute the coefficient $y$ with value of 50 to give the coefficient $\mathrm{x}$ value of 35.51 , which equal to $\mathrm{IC}_{50}$ value of $35.51 \mathrm{ppm}$ for ethanolic extract of $A$ muricata. The relationship between the concentration of ethanolic extract and the percent of inhibition is shown in fig. 2.

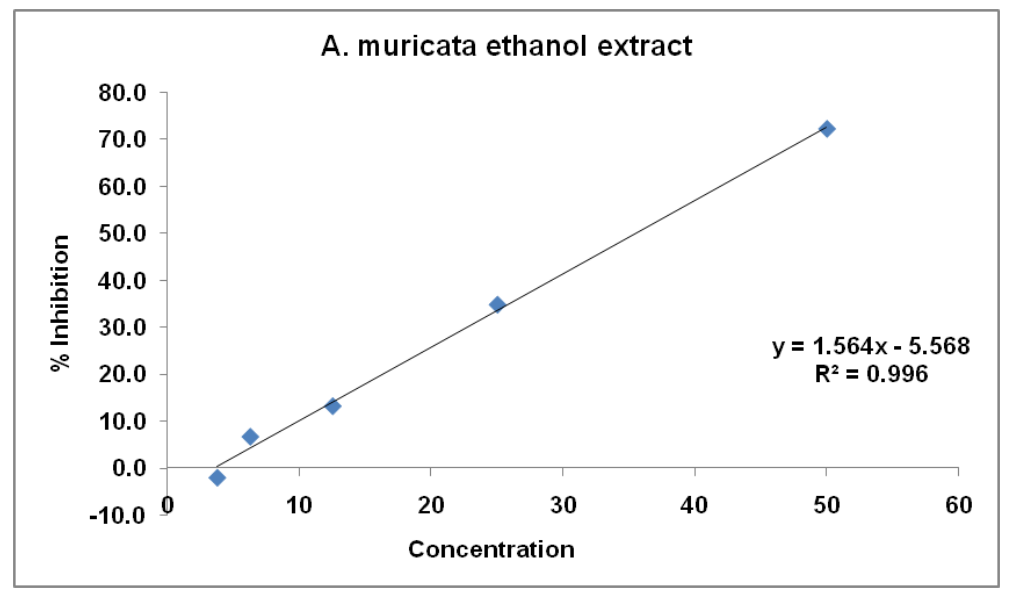

Fig. 3: Relationship between concentration of $A$. muricata ethanol extract and percentage of inhibition

Table 4: Antioxidant activity of $A$. muricata ethyl acetate extract

\begin{tabular}{lll}
\hline Concentrations of $\boldsymbol{A}$. muricata Ethyl acetate extract & \% Inhibition & SD \\
\hline 3.75 & -4.8 & 0.0257 \\
6.25 & -3.8 & 0.0470 \\
12.5 & -3.6 & 0.0304 \\
25 & -1.7 & 0.0122 \\
50 & 1.3 & 0.0391 \\
\hline
\end{tabular}

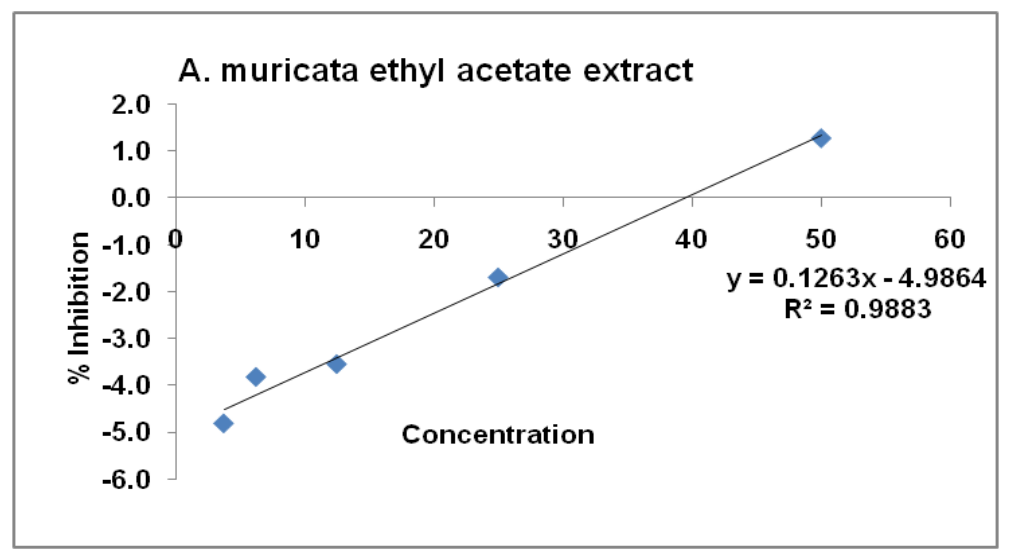

Fig. 4: Relationship between concentration of $A$. muricata ethanol extract and percent of inhibition

We used the same way as ethanolic extract to determine the $\mathrm{IC}_{50}$ value of ascorbic acid and ethyl acetate extract of A. muricata. So that, the ethyl acetate extract of $A$. muricata with $\mathrm{IC}_{50}$ value of $435.36 \mathrm{ppm}$ was determined by linier regression equation of $y=0.1263 x-4.9864$ with $\mathrm{R}^{2}=0.9883$. The relationship between the concentration of ethyl acetate extract and the percentage of inhibition is shown in fig. 4. The $\mathrm{IC}_{50}$ value of ascorbic acid as a positive control was $4.97 \mathrm{ppm}$.

In previous studies, the potency of antioxidant activity was classified into three different categories based on $\mathrm{IC}_{50}$ value. Very strong antioxidant activity was defined as a compound with an $\mathrm{IC}_{50}$ value less than $50 \mathrm{ppm}$, potential antioxidant was a compound with an $\mathrm{IC}_{50}$ value of $50-100 \mathrm{ppm}$, and a compound with an $\mathrm{IC}_{50}$ value of more than $150 \mathrm{ppm}$ tends to have no antioxidant effect [5]. Table 5 displays antioxidant activity of $A$. muricata extracts. As shown in table 5, ethanolic extract of $A$. muricata with $\mathrm{IC}_{50}$ value of $35.51 \mathrm{ppm}$ is assigned to have a very strong antioxidant activity. Whereas ethyl acetate extract of $A$. muricata with $\mathrm{IC}_{50}$ value of $435.36 \mathrm{ppm}$ showed no antioxidant activity. 
Table 5: Antioxidant activity (IC 50 value in $\mathrm{ppm}$ ) of Annona muricata extracts

\begin{tabular}{ll}
\hline Extract & IC $_{\mathbf{5 0}}$ value (ppm) \\
\hline Ethanol & 35.51 \\
Ethyl acetate & 435.36 \\
\hline
\end{tabular}

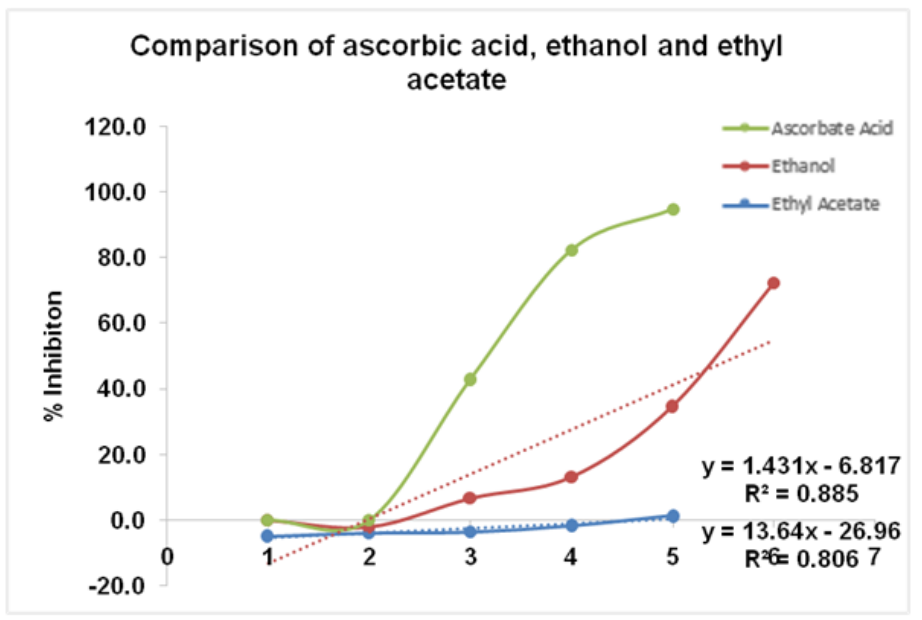

Fig. 5: Antioxidant activity of ascorbic acid, ethanol and ethyl acetate extracts of $A$. muricata

Results in fig. 5 above showed that antioxidant activity of ethanol and ethyl acetate extracts of A. muricata are lower than positive control of ascorbic acid. Compared to semi-polar ethyl acetate extract, polar ethanolic extract of $A$. muricata have more potent antioxidant activity. In a previous study, Barchan et al. reported that an increase in solvent polarity yielded a higher content of polyphenols [14]. It is well known that a significant number of phenolic compounds have good correlation with radical scavenging activity. Thus, polarity of the solvent determines antioxidant activity of the extracts.

\section{CONCLUSION}

Soursop leaves were extracted into ethanol, ethyl acetate and nhexane through maceration. The phytochemistry profile of $A$. muricata has shown that the extracts are positive for steroids, alkaloids, glycosides and tannins. Ethanolic extract is known to contain more secondary metabolites than ethyl acetate and n-hexane extracts. Ethanolic extract was demonstrated to be the most potent and is classified as a very strong antioxidant against free radical $\mathrm{DPPH}$, with an IC ${ }_{50}$ value of $35.51 \mathrm{ppm}$. Meanwhile, the IC $\mathrm{C}_{50}$ value of the ethyl acetate extract was very low and tends to have no antioxidant activity. Therefore, an ethanolic extract of Annona muricata could be developed as the next promising natural antioxidant source.

\section{ACKNOWLEDGMENT}

This article was presented in the $3^{\text {rd }}$ International Conference and Exhibition on Indonesian Medical Education and Research Institute (ICE on IMERI 2018), Faculty of Medicine, Universitas Indonesia, Jakarta, Indonesia. We thank the $3^{\text {rd }}$ ICE on IMERI Committee who had supported the peer review and manuscript preparation before submitting to the journal. We wish to express our gratitude to the Directorate of Research and Public Service (DRPM) and the Faculty of Medicine, University of Indonesia for the research grant of Publikasi Internasional Terindeks Scopus Untuk Tugas Akhir Mahasiswa (PITTA) for the fiscal year 2018.

\section{AUTHORS CONTRIBUTIONS}

All the author have contributed equally

\section{CONFLICT OF INTERESTS}

The authors declare that there is no conflict of interests regarding the establishment of this paper

\section{REFERENCES}

1. Sies H, Jones D. Oxidative stress. In: Fink G. editor. Encyclopedia of stress. 2nd ed. San Diego: Elsevier; 2007. p. 45-8.

2. Birben E, Sahiner UM, Sackesen C, Erzurum S, Kalayci O. Oxidative stress and antioxidant defense. WAO J 2012;5:9-19.

3. Mahjoub S, Roudsari JM. Role of oxidative stress in pathogenesis of metabolic syndrome. Casp J Intern Med 2012;3:386-96.

4. Ichiishi E, Li XK, Iorio EL. Oxidative stress and diseases: clinical trials and approaches. Oxid Med Cell Longev 2016:1-3. Doi: $10.1155 / 2016 / 3458276$

5. Muawanah M, Ahmad A, Natsir H. Antioxidant activity and toxicity polysaccharide extract from red algae Eucheuma cottonii and Eucheuma spinosum. Mar Chim Acta 2016;17:15-23.

6. Mohan S, Nandhakumar L. Role of various flavonoids: hypotheses on novel approach to treat diabetes. J Med Hypotheses Ideas 2014;8:1-6.

7. Istasse T, Jacquet N, Berchem T, Haubruge E, Nguyen BK, Richel A. Extraction of honey polyphenols: method development and evidence of cis isomerization. Anal Chem Insights 2016;16:49-57.

8. Quilez AM, Fernandez Arche MA, Garcia Gimenez MD, De la Puerta R. Potential therapeutic applications of the genus annona: local and traditional uses and pharmacology. J Ethnopharmacol 2018;225:244-70.

9. Pai BHM, Rajesh G, Shenoy R, Rao A. Anti-microbial efficacy of soursop leaf extract (Annona muricata) on oral pathogens: an in vitro study. J Clin Diagnostic Res 2016;10:ZC01-ZC04.

10. Astirin OP, Prayitno A, Artanti AN, Fitria MS, Witianingsih DA, Pranatami DA, et al. The expression of p53 and hsp70 proteins after treatment with Annona muricata linn leaf for activating apoptotic and lead to homeostasis program of raji cells technical report abstract. Int J Cancer Oncol 2014;2:1-6.

11. Olakunle S, Onyechi 0 , James 0 . Toxicity, anti-lipid peroxidation, in vitro and in vivo evaluation of antioxidant activity of Annona muricata ethanol stem bark extract. Am J Life Sci 2014;2:271-7.

12. Moghadamtousi SZ, Rouhollahi E, Karimian H, Fadaeinasab M, Firoozinia M, Abdulla MA, et al. The chemopotential effect of Annona muricata leaves against azoxymethane-induced colonic aberrant crypt foci in rats and the apoptotic effect of acetogenin annomuricin E in HT-29 cells: a bioassay-guided approach. PLoS One 2015;10:1-28.

13. George VC, Kumar DN, Suresh PK, Kumar RA. Antioxidant, DNA protective efficacy and HPLC analysis of Annona muricata (soursop) extracts. J Food Sci 2015;52:2328-35. 
14. Barchan A, Bakkali M, Arakrak A, Pagan R, Laglaoui A. The effects of solvents polarity on the phenolic contents and antioxidant activity of three mentha species extracts. Int J Curr Microbiol Appl Sci 2014;3:399-412.

15. Radji M, Kurniati M, Kiranasari A. Comparative antimycobacterial activity of some Indonesian medicinal plants against multi-drug resistant mycobacterium tuberculosis. J Appl Pharm Sci 2015;5:19-22.

16. Coria Tellez AV, Montalvo Gonzalez E, Yahia EM, Obledo Vazquez EN. Annona muricata: a comprehensive review on its traditional medicinal uses, phytochemicals, pharmacological activities, mechanisms of action and toxicity. Arab J Chem 2018;11:662-91.

17. Gavamukulya Y, Wamunyokoli F, El-Shemy HA. Annona muricata: is the natural therapy to most disease conditions including cancer growing in our backyard? A systematic review of its research history and future prospects. Asian Pac J Trop Med 2017;10:835-48.

18. Moghadamtousi SZ, Fadaeinasab M, Nikzad S, Mohan G, Ali HM Kadir HA. Annona muricata (Annonaceae): a review of its traditional uses, isolated acetogenins and biological activities. Int J Mol Sci 2015;16:15625-58.

19. Wulandari L, Lestyo. Kromatografi Lapis Tipis; 2016. p. 1-182.

20. Moon JK, Shibamoto T. Antioxidant assays for plant and food components. J Agric Food Chem 2009;57:1655-66.

21. Molyneux $P$. The use of the stable free radical diphenylpicrylhydrazyl (DPPH) for estimating antioxidant activity. Songklanakarin J Sci Technol 2004;26:211-9. 